\title{
FAKTOR - FAKTOR PENDUKUNG SELF CARE MANAGEMENT DIABETES MELLITUS TIPE 2: A LITERATURE REVIEW
}

\author{
Factors Supporting Self-Care Management On Diabetes Mellitus Type 2 \\ Patients: A Literature Review
}

\author{
Fitri A. Sabil ${ }^{1}$, Kusrini S. Kadar ${ }^{2}$, Elly Lilianty Sjattar ${ }^{3}$ \\ 1,2,3 Program Studi Magister Ilmu Keperawatan Fakultas Keperawatan \\ Universitas Hasanuddin Makassar \\ Email : fitrisabil90@gmail.com
}

\begin{abstract}
ABSTRAK
Latar belakang : Diabetes Melitus tipe 2 merupakan diabetes melitus yang paling sering dijumpai dan merupakan penyakit yang tidak dapat disembuhkan. Tingginya angka kejadian Diabetes mellitus ini menjadi tantangan bagi masyarakat dan tenaga kesehatan khususnya perawat dalam mencegah komplikasi yang lebih jauh dengan cara melakukan managemen perawatan diri (Self care management) yang tepat. Tujuan : Untuk mengetahui faktor- faktor yang mendukung self care managemen yang tepat pada pasien diabetes mellitus tipe 2. Metode : Data base yang digunakan dalam pembuatan literatur review ini adalah Google Scholar, Science Direct dan Pubmed. Didapatkan 58 artikel terkait self care management dan diabetes mellitus tipe 2 yang diidentifikasi dan dipublikasikan dari tahun 2009-2017. Dari 58 artikel 10 artikel yang memenuhi syarat review. Hasil : Dari 10 artikel di dapatkan bahwa faktor- faktor yang mendukung self care management adalah health literacy, self efficacy dan dukungan keluarga. Namun dari beberapa hasil penelitian tersebut health literacy dan self efficacy merupakan faktor yang lebih mendominasi untuk mendukung Self care management yang tepat. Kesimpulan : Health literacy dan self efficacy merupakan faktor yang mendukung Self care management yang tepat. Namun masih dibutuhkan beberapa literatur untuk mengetahui lebih jauh pengaruh kedua faktor tersebut terhadap self care management.
\end{abstract}

Kata Kunci : Diabetes melitus tipe 2, health literacy, self efficacy, dukungan keluarga, self care management.

\begin{abstract}
Background: Type 2 diabetes mellitus is the most common diabetes and is an incurable disease. Due to its high prevalence, it is a challenge for both the community and health care workers, especially nurses in preventing further complications by conducting a proper self-care management. Objective: This study aimed to determine the factors that can support proper self-care management in patients with type 2 diabetes mellitus. Method: This study used the database from Google Scholar, Science Direct, and Pubmed in making the review literature. There were 58 articles published from 2009 to 2017 related to self-care management and type 2 diabetes mellitus that were identified. However, of 58 articles, only 11 articles met with the review requirements. Result: Based on the 11 articles that have been reviewed, this study showed that the factors that are able to support self-care management are health literacy, self-efficacy and family support. However, health literacy and selfefficacy are the most dominating factors to support proper self-care management. Conclusion: Health literacy and self-efficacy are two factors that are able to support proper self-care management. However, this study still needs some literatures to find out more about the influence of these two factors on self-care management.
\end{abstract}

Keywords: type 2 diabetes mellitus, health literacy, self efficacy, family support, self-care management. 


\section{LATAR BELAKANG}

Diabetes Melitus tipe 2 merupakan diabetes melitus yang paling sering dijumpai dan merupakan penyakit yang tidak dapat disembuhkan tetapi dapat dikendalikan dan dapat menimbulkan masalah serta komplikasi stroke, gagal ginjal, retinopati, neuropati dan lainlain (American Diabetes Association, 2010; Webb, Rheeder, \& Zyl, 2014). Didapatkan laporan dari 130 negara pada tahun 2013 bahwa 382 juta orang menderita diabetes dan diperkirakan akan meningkat menjadi 592 juta pada tahun 2035 (Guariguata et al., 2014).

Di Indonesia didapatkan data dari Perkumpulan Endokrinologi Indonesia bahwa pada tahun 2015, yang menderita diabetes melitus mencapai 9.1 juta orang, sehingga menempati urutan ke 5 terbanyak penderita diabetes melitus setelah Negara Cina, India, USA dan Brazil, yang sebelumnya menempati urutan ke 7 pada tahun 2013 (PERKENI, 2015). Dengan demikian, DM membutuhkan self care management yang tepat agar dapat mencegah terjadinya komplikasi pada penderita.

Prevalensi komplikasi penderita diabetes melitus tipe 2 ini cenderung meningkat dan semakin memburuk disebabkan karena ketidak mampuan penderita dalam mengelola penyakitnya secara mandiri (American Diabetes Association, 2010). Dalam hal ini manajemen diri menjadi sangat penting dalam pengobatan diabetes mellitus. Perawatan diri adalah salah satu manajemen diri diabetes mellitus dan perlu untuk mendapatkan kontrol glikemik yang memadai (Safila, 2015). Pada dasarnya semua manusia mempunyai kebutuhan untuk melakukan perawatan diri dan mempunyai hak untuk melakukan perawatan diri secara mandiri. Menurut Dorothea E. Orem (2001) Perawatan diri merupakan kebutuhan manusia dimana individu berusaha menjaga, mempertahankan serta meningkatkan kualitas hidup pasien untuk kehidupan, kesejahteraan serta penyembuhan dari penyakit dan terhindar dari komplikasi (Alligood, 2014).

Keberhasilan dari program managemen penyakit kronis tidak lepas dari, kemampuan individu dalam mengakses, memahami, dan menggunakan informasi dan pelayanan kesehatan untuk membuat keputusan tentang perawatan kesehatannya yang dikenal dengan Health Literacy (Berkman, Davis, \& McCormack, 2010). Tujuan dari studi literatur ini adalah untuk mengetahui faktor-faktor yang mendukung self care managemen yang tepat.

\section{METODE}

Dari 10 jurnal yang yang direview, didapatkan 8 jurnal yang memiliki desain cross sectional (Berkman et al., 2010; Bohanny et al., 2013; Fatima Al Sayah, Sumit R. Majumdar, Beverly Williams, Sandy Robertson, 2012; Isomah (2009); Heijmans, Waverijn, Rademakers, van der Vaart, \& Rijken, 2015; Jones et al., 2011; Mulyati et al., 2013; Osborn, Cavanaugh, Wallston, \& Rothman, 2010) dan 2 jurnal yang menggunakan Korelasional deskriptif (Kav S , Yilmaz AA , Bulut Y, 2015; Masoompour, Tirgari, \& Ghazanfari, 2017)

Studi literatur ini melalui penelusuran hasil publikasi ilmiah dengan rentang tahun 2009-2017 dengan menggunakan database Google Scholar, Science Direct, dan Pubmed. Dengan menggunakan kata kunci diabetes mellitus type 2 AND self care management AND health literacy AND self efficacy AND dukungan keluarga. 


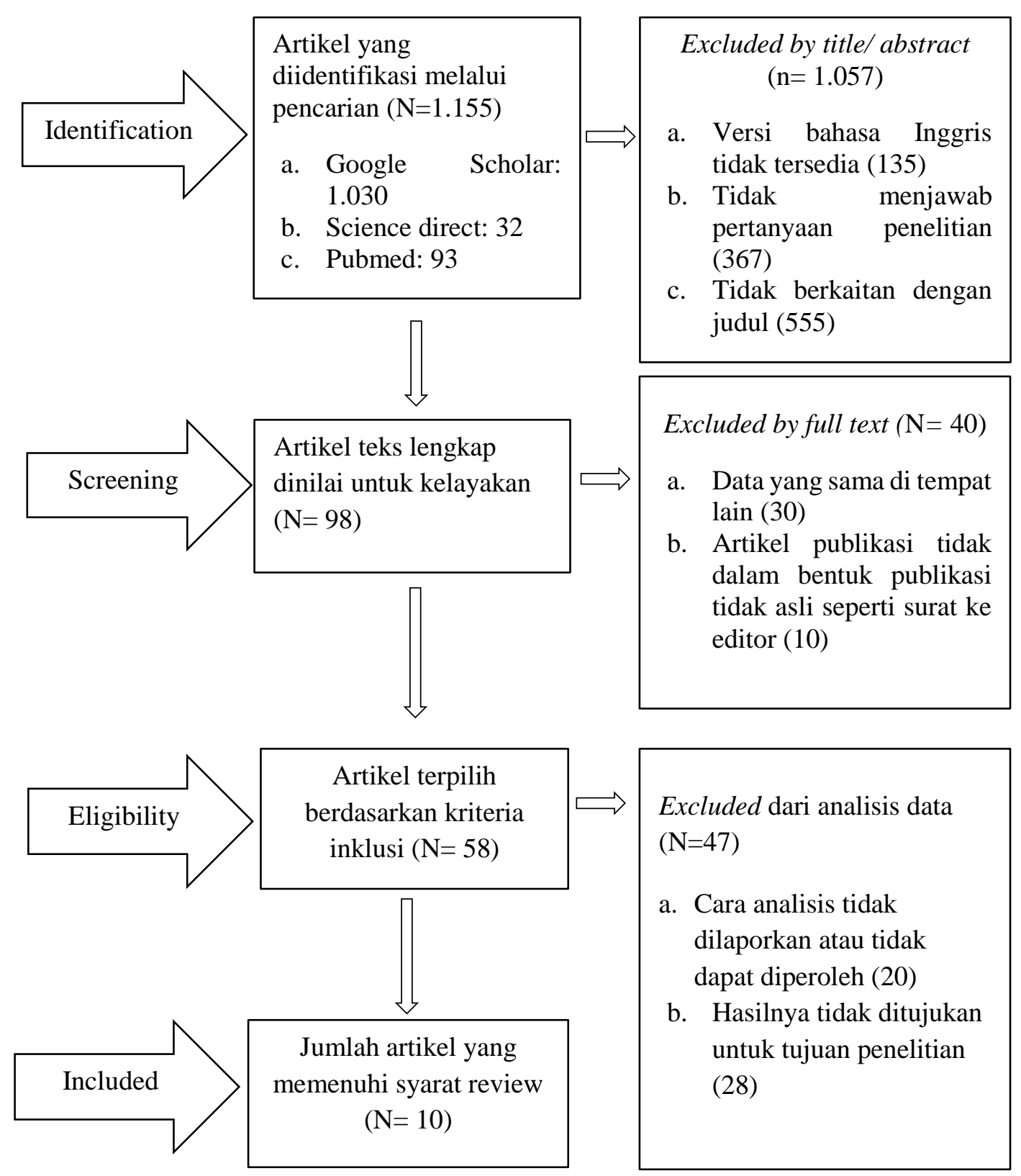

Gambar 1. Proses Pencarian Artikel 
Tabel 1. Studi Karakteristik

\begin{tabular}{|c|c|c|c|c|}
\hline No & $\begin{array}{c}\text { Penulis } \\
\text { (Tahun) }\end{array}$ & Tujuan & $\begin{array}{c}\text { Desain } \\
\text { Penelitian / } \\
\text { Responden }\end{array}$ & Hasil Penelitian \\
\hline
\end{tabular}

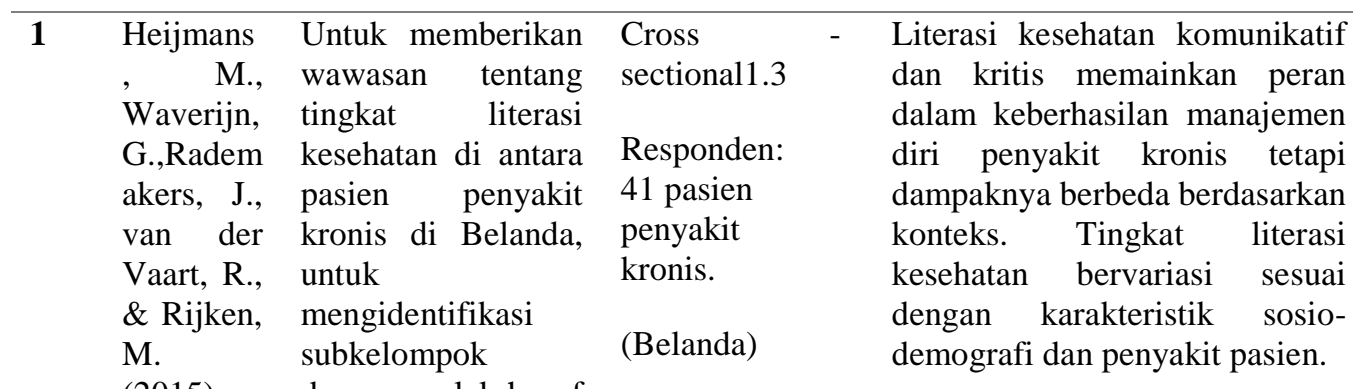

(2015). dengan melek huruf yang rendah dan untuk memeriksa hubungan antara melek kesehatan dan manajemen diri.

\begin{tabular}{llll}
\hline Isomah & untuk & Cross \\
(2009) & $\begin{array}{l}\text { mengidentifikasi } \\
\text { faktor-faktor }\end{array}$ & sectional \\
& & Responden: \\
& yang berhubungan & 135 pasien \\
dengan self care & DM di \\
& management pasien & Rumah \\
& DM di Rumah Sakit & Sakit Panti \\
& Panti Wilasa & Wilasa \\
& Citarum Semarang. & Citarum \\
& Semarang.
\end{tabular}

Terdapat hubungan yang
signifikan antara pengetahuan
DM, keyakinan tentang kemampuan diri, dukungan keluarga dan lama sakit DM dengan self care management DM ( $p<0,05)$. Faktor-faktor yang mempunyai hubungan paling signifikan dengan self care management DM adalah keyakinan tentang kemampuan diri dan dukungan keluarga. Responden yang mempunyai keyakinan tentang kemampuan diri berpeluang 20 kali untuk melaksanakan self care management DM baik dibanding dengan yang kurang mempunyai keyakinan tentang kemampuan diri $\quad(\mathrm{OR}=20,12)$. Sedangkan responden yang mendapat dukungan keluarga baik berpeluang 10 kali untuk melaksanakan self care management DM baik dibanding dengan yang tidak mendapat dukungan keluarga $(\mathrm{OR}=10,30)$.

\begin{tabular}{lllll}
\hline 3 & Masoomp & Untuk menyelidiki & Korelasional & Usia rata-rata peserta adalah \\
our, & hubungan antara deskriptif & & $55,1 \pm 10,1$ tahun dan $74,75 \%$ \\
Tirgari, \& & melek kesehatan, & & dari mereka adalah laki-laki. \\
Ghazanfa & self-efficacy, dan & Responden: & Nilai rata-rata perilaku \\
ri, 2017 & perilaku perawatan & 400 pasien & perawatan diri, melek kesehatan, \\
& diri pada pasien dengan & dan self-efficacy adalah 61,94 \\
& diabetes. & diabetes & $14,35,63,6 \pm 20,7$, dan $146,3 \pm$ \\
& & yang dirujuk & 22,9, masing-masing. Selain itu, \\
\hline
\end{tabular}




\begin{tabular}{|c|c|c|c|c|c|}
\hline & & & $\begin{array}{l}\text { ke klinik } \\
\text { diabetes } \\
\text { selama } 2015 \\
\text { (Iran) }\end{array}$ & & $\begin{array}{l}\text { hasil koefisien korelasi Pearson } \\
\text { menunjukkan korelasi langsung } \\
\text { yang signifikan antara literasi } \\
\text { kesehatan dan self-efficacy }(\mathrm{P}= \\
0,03, \mathrm{r}=0,1) \text {, serta perilaku } \\
\text { melek kesehatan dan perawatan } \\
\text { diri }(\mathrm{P}=0,04, \mathrm{r}=0,1) \text {. } \\
\text { Selanjutnya, self-efficacy } \\
\text { memiliki korelasi langsung yang } \\
\text { signifikan dengan perilaku } \\
\text { perawatan diri }(\mathrm{P}<0,001, \mathrm{r}= \\
0,5) \text {. }\end{array}$ \\
\hline 4 & $\begin{array}{l}\text { Jones et } \\
\text { al., } 2011\end{array}$ & $\begin{array}{l}\text { Untuk } \\
\text { mengembangkan } \\
\text { dan menguji } \\
\text { penerimaan pamflet } \\
\text { pendidikan } \\
\text { hipertensi publik } \\
\text { yang disesuaikan } \\
\text { agar sesuai dengan } \\
\text { kebutuhan populasi } \\
\text { Indo-Asia lokal } \\
\text { yang berisiko, di } \\
\text { Calgary, Alberta, } \\
\text { Kanada. }\end{array}$ & $\begin{array}{l}\text { Cross } \\
\text { sectional } \\
\text { Responden: } \\
\text { Masyarakat } \\
\text { Kanada } \\
\text { yang } \\
\text { memiliki } \\
\text { peningkatan } \\
\text { risiko } \\
\text { penyakit } \\
\text { kardiovasku } \\
\text { lar. }\end{array}$ & - & $\begin{array}{l}\text { Lima puluh sembilan peserta } \\
\text { berbahasa Inggris mengevaluasi } \\
\text { dan mengkonfirmasi validitas } \\
\text { konsep versi bahasa Inggris yang } \\
\text { diadaptasi. } 28 \text { peserta yang tidak } \\
\text { berbahasa Inggris mengevaluasi } \\
\text { versi terjemahan Gujarati }(\mathrm{N}= \\
\text { 13) dan Punjabi }(\mathrm{N}=15) \text { dari } \\
\text { pamflet yang disesuaikan. } \\
\text { Semua peserta menemukan } \\
\text { pamflet yang diterima dan } \\
\text { merasa mereka telah } \\
\text { meningkatkan pemahaman } \\
\text { mereka tentang hipertensi. } \\
\text { Health literacy dapat } \\
\text { meningkatkan pengetahuan } \\
\text { kesehatan serta membantu } \\
\text { masyarakat dalam mengambil } \\
\text { keputusan yang tepat tentang } \\
\text { kesehatan mereka. }\end{array}$ \\
\hline 5 & $\begin{array}{l}\text { Osborn, } \\
\text { Cavanaug } \\
\text { h,Wallsto } \\
\text { n, \& } \\
\text { Rothman, } \\
2010\end{array}$ & $\begin{array}{l}\text { Untuk melihat peran } \\
\text { self-efficacy } \\
\text { diabetes dalam jalur } \\
\text { prediksi yang } \\
\text { menghubungkan } \\
\text { melek kesehatan } \\
\text { dan berhitung } \\
\text { dengan kontrol } \\
\text { glikemik (A1C). }\end{array}$ & $\begin{array}{l}\text { Cross } \\
\text { sectional } \\
\text { Responden: } \\
383 \text { pasien } \\
\text { DM tipe 1 } \\
\text { dan } 2 \text { di } \\
\text { klinik } \\
\text { khusus } \\
\text { diabetes } \\
\text { (Chapel } \\
\text { Hill, North } \\
\text { Carolina } \\
\text { dan } \\
\text { Nashville, } \\
\text { Tennessee) }\end{array}$ & - & $\begin{array}{lr}\text { Diabetes self-efficacy menjadi } & \text { me } \\
\text { target penting dari intervensi } \\
\text { untuk meningkatkan kontrol } \\
\text { diabetes dan mempromosikan } \\
\text { kesetaraan kesehatan yang } \\
\text { berkaitan dengan kemampuan } \\
\text { melek kesehatan dan } \\
\text { keterampilan berhitung umum } \\
\text { yang diperlukan } \\
\text { manajemen diabetes. }\end{array}$ \\
\hline 6 & $\begin{array}{l}\text { Al Sayah, } \\
\text { Sumit R. } \\
\text { Majumda } \\
\text { r, Beverly } \\
\text { Williams, } \\
\text { Sandy }\end{array}$ & $\begin{array}{lr}\text { untuk mengetahui } \\
\text { tingkat } & \text { health } \\
\text { literacy pasien di } \\
\text { Klinik } r \text { Dokter } \\
\text { Keluarga } \text { Fakultas } \\
\text { Kedokteran } \\
\text { Universitas }\end{array}$ & $\begin{array}{l}\text { Cross } \\
\text { sectional } \\
\text { Responden: } \\
\text { Pasien di } \\
\text { Klinik } \\
\text { Dokter }\end{array}$ & - & $\begin{array}{l}\text { Health literacy yang rendah } \\
\text { secara konsisten dikaitkan } \\
\text { dengan pengetahuan diabetes } \\
\text { yang lebih buruk. } \\
\text { Health literacy yang rendah } \\
\text { dianggap sebagai penghalang } \\
\text { potensial untuk meningkatkan }\end{array}$ \\
\hline
\end{tabular}




\begin{tabular}{|c|c|c|c|c|}
\hline & $\begin{array}{l}\text { Robertso } \\
\mathrm{n},(2012)\end{array}$ & $\begin{array}{l}\text { Indonesia (KDK } \\
\text { FKUI) Kiara dan } \\
\text { faktor-faktor yang } \\
\text { berhubungan } \\
\text { dengan tingkat } \\
\text { kemelekan } \\
\text { kesehatan tersebut. }\end{array}$ & $\begin{array}{l}\text { Keluarga } \\
\text { Fakultas } \\
\text { Kedokteran } \\
\text { Universitas } \\
\text { Indonesia } \\
\text { Kiara }\end{array}$ & $\begin{array}{l}\text { hasil kesehatan pada pasien } \\
\text { diabetes dan kondisi } \\
\text { lainnya, serta. }\end{array}$ \\
\hline 7 & $\begin{array}{l}\text { Kav S } \\
\text { Yilmaz } \\
\text { AA Bulut } \\
\text { Y, (2015) }\end{array}$ & $\begin{array}{l}\text { Penelitian ini } \\
\text { bertujuan untuk } \\
\text { menyelidiki } \\
\text { aktivitas perawatan } \\
\text { diri, depresi dan } \\
\text { self-efficacy di } \\
\text { antara orang-orang } \\
\text { dengan diabetes tipe } \\
2 \text { di Turki. }\end{array}$ & $\begin{array}{l}\text { Korelasional } \\
\text { Responden: } \\
200 \text { pasien } \\
\text { dengan } \\
\text { diabetes tipe } \\
2 \text { dari klinik } \\
\text { rawat jalan } \\
\text { endokrinolo } \\
\text { gi di rumah } \\
\text { sakit } \\
\text { universitas } \\
\text { (Turki) }\end{array}$ & $\begin{array}{l}\text { Hubungan antara self-efficacy } \\
\text { dan aktivitas perawatan diri } \\
\text { adalah positif. Intervensi untuk } \\
\text { meningkatkan self-efficacy } \\
\text { pasien dan perawatan diri } \\
\text { diperlukan } \\
\text { memaksimalkan manajemen diri } \\
\text { diabetes. }\end{array}$ \\
\hline 8 & $\begin{array}{l}\text { Bohanny } \\
\text { et al., } \\
(2013)\end{array}$ & $\begin{array}{l}\text { Tujuan penelitian } \\
\text { adalah untuk } \\
\text { mengeksplorasi } \\
\text { hubungan antara } \\
\text { melek kesehatan, } \\
\text { self-efficacy, dan } \\
\text { perilaku perawatan } \\
\text { diri pasien dengan } \\
\text { diabetes tipe } 2 .\end{array}$ & $\begin{array}{l}\text { Cross } \\
\text { sectional } \\
\text { Responden: } \\
150 \text { pasien } \\
\text { diabetes tipe } \\
2 \text { direkrut } \\
\text { dari klinik } \\
\text { diabetes di } \\
\text { Kepulauan } \\
\text { Marshall. } \\
\text { (Taiwan) }\end{array}$ & $\begin{array}{l}\text { Literasi kesehatan, menerima } \\
\text { pendidikan diabetes, dan status } \\
\text { pekerjaan bersama-sama } \\
\text { menjelaskan } 11,8 \% \text { dari varians } \\
\text { dalam self-efficacy (F }((3,147)) \\
=7,58, \mathrm{p}<0,001) \text {. Pasien yang } \\
\text { memiliki literasi kesehatan yang } \\
\text { lebih tinggi, menerima lebih } \\
\text { banyak pendidikan terkait } \\
\text { diabetes, saat ini bekerja dan } \\
\text { memiliki self-efficacy yang } \\
\text { lebih baik. Self-efficacy dan } \\
\text { status perkawinan bersama-sama } \\
\text { menjelaskan } 16,7 \% \text { dari varians } \\
\text { dalam perilaku perawatan diri }(\mathrm{F} \\
((2,148))=15,96 \text {, p <0,001). } \\
\text { Pasien yang memiliki self- } \\
\text { efficacy lebih tinggi dan yang } \\
\text { menikah memiliki perilaku } \\
\text { perawatan diri yang lebih baik. }\end{array}$ \\
\hline 9 & $\begin{array}{l}\text { (Mulyati } \\
\text { et al., } \\
2013)\end{array}$ & $\begin{array}{l}\text { mengidentifikasi } \\
\text { faktor- faktor yang } \\
\text { mempengaruhi Self } \\
\text { Management } \\
\text { Behaviour dan } \\
\text { menganalisis faktor } \\
\text { yang paling } \\
\text { dominan } \\
\text { memengaruhi Self } \\
\text { Management } \\
\text { Behaviour pada } \\
\text { pasien hipertensi di } \\
\text { Rumah Sakit Umum }\end{array}$ & $\begin{array}{l}\text { Cross } \\
\text { sectional } \\
\text { Responden: } \\
\text { Pasien } \\
\text { hipertensi di } \\
\text { Rumah } \\
\text { Sakit Umum } \\
\text { Daerah } 45 \\
\text { Kuningan. }\end{array}$ & $\begin{array}{l}\text { Dukungan sosial yang diberikan } \\
\text { oleh keluarga dan teman } \\
\text { memiliki hubungan dengan } \\
\text { perilaku SMB (p-value sebesar } \\
0.015 \text { ) dan nilai odds ratio } \\
\text { sebesar 2,87 (1,29-6,37) dimana } \\
\text { responden yang mendapatkan } \\
\text { dukungan sosial yang baik } \\
\text { diprediksi dapat menunjukkan } \\
\text { kemampuan perilaku SMB yang } \\
\text { baik sebesar 2,87 kali lebih } \\
\text { tinggi dibandingkan dengan }\end{array}$ \\
\hline
\end{tabular}




\begin{tabular}{|c|c|c|c|c|c|}
\hline & & $\begin{array}{l}\text { Daerah } \\
\text { Kuningan. }\end{array}$ & & & $\begin{array}{l}\text { responden yang mendapatkan } \\
\text { dukungan sosial yang kurang. }\end{array}$ \\
\hline 10 & $\begin{array}{l}\text { (Berkman } \\
\text { et al., } \\
2010)\end{array}$ & $\begin{array}{l}\text { Untuk mengukur } \\
\text { kebutuhan literasi } \\
\text { fungsional dari } \\
\text { populasi orang } \\
\text { dewasa. }\end{array}$ & $\begin{array}{l}\text { Cross } \\
\text { sectional } \\
\text { Responden: } \\
\text { Masyarakat } \\
\text { orang } \\
\text { dewasa } \\
\text { (Amerika } \\
\text { Serikat) }\end{array}$ & - & $\begin{array}{l}\text { Keterampilan literasi yang rumit } \\
\text { semakin dibutuhkan untuk } \\
\text { berfungsi dalam masyarakat dan } \\
\text { rendahnya tingkat health literacy } \\
\text { dapat berdampak pada kesehatan } \\
\text { dan perawatan kesehatan. }\end{array}$ \\
\hline
\end{tabular}

\section{HASIL DAN PEMBAHASAN}

Berdasarkan hasil pencarian literatur dari 58 artikel yag didapatkan, terdapat 11 artikel yang memenuhi kriteria inklusi. Penelitian-penelitian tersebut mengidentifikasi faktor- faktor yang dapat menunjang penerapan self care managemen yang tepat yaitu health literacy, self efficacy dan dukungan keluarga.

\section{Health literacy}

Keberhasilan dari program managemen penyakit kronis tidak lepas dari, kemampuan individu dalam mengakses, memahami, dan menggunakan informasi dan pelayanan kesehatan untuk membuat keputusan tentang perawatan kesehatannya yang dikenal dengan Health Literacy Berkman, Davis, \& McCormack, (2010).

Menurut Heijmans, Waverijn, Rademakers, van der Vaart, \& Rijken, (2015); Kanj \& Mitic (2009) menemukan bahwa dengan tingkat health literacy yang rendah terjadi peningkatan angka penyakit kronis sebesar $47 \%$ dari total beban penyakit, dan health literacy memerankan peran penting dalam manajemen penyakit kronis. Health literacy pada setiap individu penting untuk diketahui karena berhubungan dengan kemampuan untuk memperoleh informasi kesehatan dalam upaya meningkatkan dan mempertahankan kesehatannya. Secara general health literacy dikatakan dapat meningkatkan pengetahuan kesehatan serta membantu individu/masyarakat dalam pengambilan keputusan yang tepat tentang kesehatan mereka (Jones et al., 2011; Nutbeam \& Kickbusc h, 2000). Health literacy yang rendah merupakan penghalang dalam meningkatkan hasil kesehatan pada pasien diabetes dan pasien dengan kondisi kronis lainnya, serta dapat menyebabkan diagnosis penyakit yang tertunda, keterampilan perawatan diri yang rendah, peningkatan penggunaan layanan darurat, tingkat rawat inap yang tinggi, peningkatan kejadian berbagai penyakit, dan pada akhirnya melipat gandakan tingkat kematian (Al Sayah, Sumit R. Majumdar, Beverly Williams, Sandy Robertson, 2012; Javadzade et al., 2012).

\section{Self efficacy}

Self-efficacy dikenal sebagai salah satu sumber daya dalam memberdayakan individu untuk melakukan tugas pribadi mereka. Self efficacy merupakan penilaian diri seseorang terhadap kemampuannya dalam mengerjakan sesuatu untuk mencapai tujuan tertentu dan juga dikenal sebagai salah satu sumber daya dalam memberdayakan individu untuk melakukan tugas pribadi mereka (Oh, Yang, Kim, Yoo, \& Lee, 2014). Penelitian 
yang dilakukan di Turki menyatakan bahwa self efficacy memiliki hubungan yang positif dalam perawatan diri pasien DM dan perawatan diri dibutuhkan dalam memaksimalkan manajemen diri diabetes (Kav S , Yilmaz AA , Bulut Y, 2015; Masoompour et al., 2017; Osborn et al., 2010). Demikian pula dengan penelitian yang dilakukan oleh Bohanny et al., (2013) menyatakan bahwa pasien yang memiliki self-efficacy lebih tinggi akan memiliki perilaku perawatan diri yang lebih baik.

\section{Dukungan keluarga}

Dukungan keluarga seperti kepedulian, bantuan, memberikan usulan, nasehat serta informasi, penting dalam meningkatkan self care management diabetes mellitus, pengontrolan glukosa darah serta mampu meningkatkan kesadaran pasien dalam melakukan tindakan perawatan diri. Penelitian yang dilakukan Ismonah, (2009); Mulyati et al., (2013) di Semarang dan Kuningan menyatakan bahwa adanya hubungan yang signifikan antara dukungan keluarga dan self care management pada diabetes mellitus. Responden yang mendapatkan dukungan dari keluarga berpeluang 10 kali untuk melakukan self care management diabetes dengan baik di banding dengan yang tidak mendapatkan dukungan keluarga. Dengan adanya hubungan yang erat antara pasien dengan anggota keluarga dan teman. Pasien dapat mencurahkan perasaan dan kesulitan yang dihadapi serta mendapatkan dukungan untuk meningkatkan kepercayaan dan harapan pasien.

Dengan demikian faktor yang dapat mempengaruhi pelaksanaan self care management yang tepat adalah health literacy, self efficacy dan dukungan keluarga, namun health literacy dan self efficacy merupakan faktor yang lebih mendominasi untuk mendukung self care management yang tepat.

\section{KESIMPULAN}

Beberapa hasil penelitian tersebut health literacy dan self efficacy merupakan faktor yang lebih mendominasi untuk mendukung Self care management yang tepat Namun masih dibutuhkan beberapa literatur untuk mengetahui lebih jauh pengaruh kedua faktor tersebut terhadap self care management.

\section{DAFTAR PUSTAKA}

Alligood, M. R. (2014). Nursing Theorists and Their Work (8th edn). Nursing Theorists and Their Work (8th edn). https://doi.org/10.5172/conu.2007.24.1.106a

American Diabetes Association. (2010). Diagnosis and classification of diabetes mellitus. Diabetes Care, 33(SUPPL. 1). https://doi.org/10.2337/dc10-S062

Berkman, N. D., Davis, T. C., \& McCormack, L. (2010). Health literacy: What is it? Journal of Health Communication, 15(SUPPL. 2), 9-19. https://doi.org/10.1080/10810730.2010.499985

Bohanny, W., Wu, S.-F. V., Liu, C.-Y., Yeh, S.-H., Tsay, S.-L., \& Wang, T.-J. (2013). Health literacy, self-efficacy, and self-care behaviors in patients with type 2 diabetes mellitus. Journal of the American Association of Nurse Practitioners, 25(9), 495502. https://doi.org/10.1111/1745-7599.12017 
Fatima Al Sayah, Sumit R. Majumdar, Beverly Williams, Sandy Robertson, J. A. J. (2012). Health Literacy and Health Outcomes in Diabetes: A Systematic Review. Journal of General Internal Medicine, 28(3), 444-452. https://doi.org/10.1007/s11606-0122241-z

Guariguata, L., Whiting, D. R., Hambleton, I., Beagley, J., Linnenkamp, U., \& Shaw, J. E. (2014). Global estimates of diabetes prevalence for 2013 and projections for 2035. Diabetes Research and Clinical Practice, 103(2), 137-149. https://doi.org/10.1016/j.diabres.2013.11.002

Heijmans, M., Waverijn, G., Rademakers, J., van der Vaart, R., \& Rijken, M. (2015). Functional, communicative and critical health literacy of chronic disease patients and their importance for self-management. Patient Education and Counseling, 98(1), 4148. https://doi.org/10.1016/j.pec.2014.10.006

Ismonah. (2008). Analsis Faktor-faktor yang berhubungan dengan self care management diabetes melitus dalam konteks asuhan keperawatan di RS Panti Wilasa Citarum Semarang.

Javadzade, S. H., Sharifirad, G., Radjati, F., Mostafavi, F., Reisi, M., \& Hasanzade, A. (2012). Relationship between health literacy, health status, and healthy behaviors among older adults in Isfahan, Iran. Journal of Education and Health Promotion, 1(August), 31. https://doi.org/10.4103/2277-9531.100160

Jones, C. A., Mawani, S., King, K. M., Allu, S. O., Smith, M., Mohan, S., \& Campbell, N. R. C. (2011). Tackling health literacy: Adaptation of public hypertension educational materials for an Indo-Asian population in Canada. BMC Public Health, 11, 14712458. https://doi.org/10.1186/1471-2458-11-24

Kav S , Yilmaz AA, Bulut Y, D. (2015). Self-efficacy, depression and self-care activities of people with type 2 diabetes in Turkey, 24(1), 27-35. Retrieved from https://www.ncbi.nlm.nih.gov/pubmed/29218959

Masoompour, M., Tirgari, B., \& Ghazanfari, Z. (2017). The Relationship between Health Behaviors in Diabetic Patients, (098 51), 16-25. https://doi.org/10.22038/EBCJ.2017.24826.1551

Mulyati, L., Yetti, K., Sukmarini, L., Tinggi, S., Kesehatan, I., Keperawatan, F. I., \& Indonesia, U. (2013). Analisis Faktor yang Memengaruhi Self Management Behaviour pada Pasien Hipertensi Analysis of Factors Effecting Self-Management Behaviour among Patients with Hypertension. Jurnal Ilmu Kesehatan Bhakti Husada, 1 nomor 2, 112-123.

Nutbeam, D., \& Kickbusch, I. (2000). Advancing health literacy: a global challenge for the 21st century. Health Promotion International, 15(3), 183-184. https://doi.org/10.1093/heapro/15.3.183

Oh, E., Yang, Y., Kim, S., Yoo, J., \& Lee, H. (2014). Level of knowledge, self-efficacy, and attitude for evidence-based practice among undergraduate nursing students. 
International Journal Of Evidence-Based Healthcare, 204. https://doi.org/10.1097/01.XEB.0000455212.87444.7c

Osborn, C. Y., Cavanaugh, K., Wallston, K. A., \& Rothman, R. L. (2010). Self-efficacy links health literacy and numeracy to glycemic control. Journal of Health Communication, 15(SUPPL. 2 2), 146-158. https://doi.org/10.1080/10810730.2010.499980

PERKENI. (2015). Pengelolaan dan pencegahan diabetes melitus tipe 2 di indonesia 2015. Pengurus Besar Perkumpulan Endokrinologi Indonesia (PB PERKENI).

Safila, I. (2015). Hubungan Antara Tingkat Literasi Kesehatan Dengan Diabetes Aktivitas Diri Perlindungan Pada Pasien Diabetes Melitus Tipe 2 Di Kabupaten Sleman. Universitas Gadjah Mada.

Webb, E. M., Rheeder, P., \& Zyl, D. G. Van. (2014). Diabetes care and complications in primary care in the Tshwane district of South Africa. Primary Care Diabetes, 8-15. https://doi.org/10.1016/j.pcd.2014.05.002 